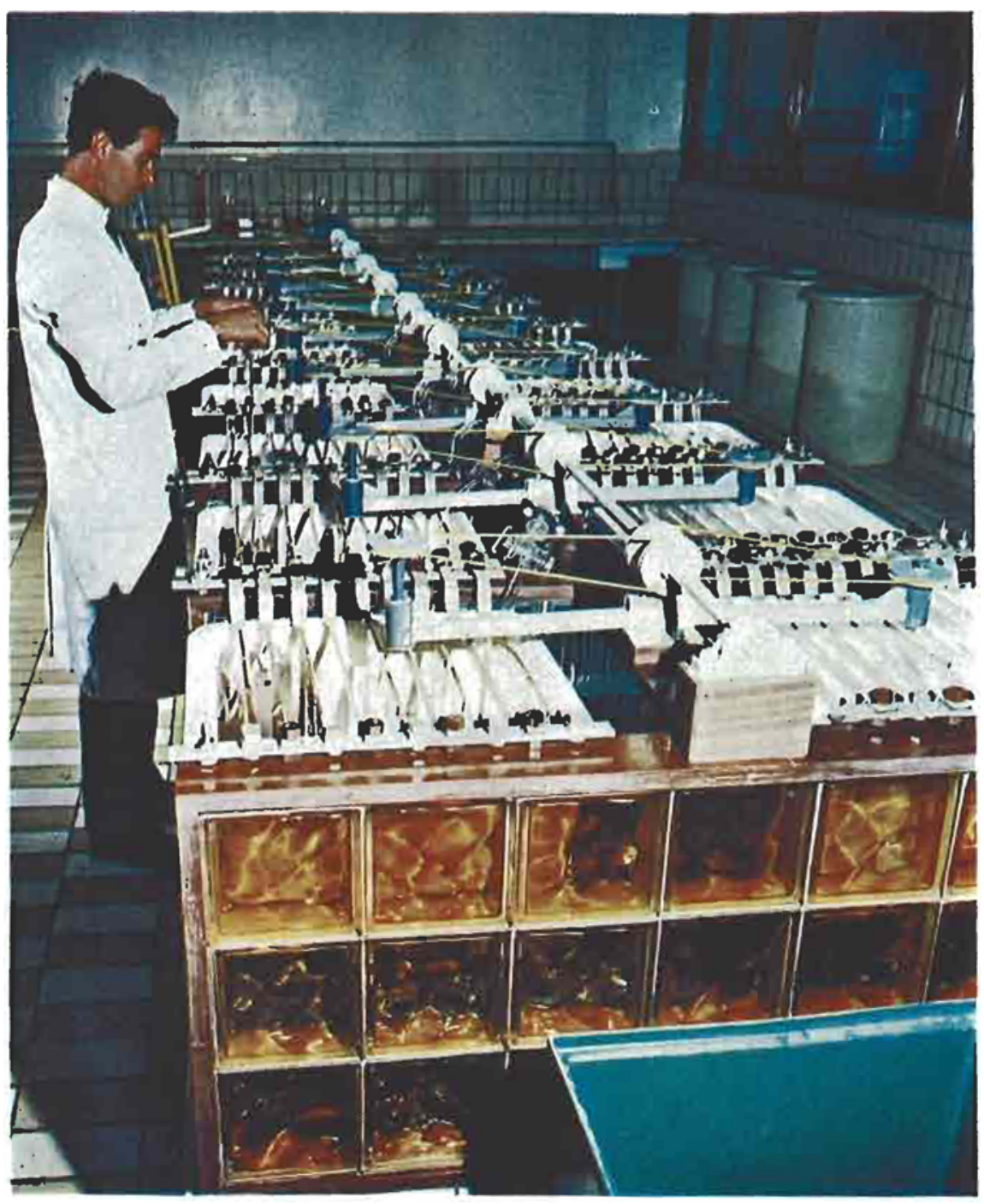

A small electrolytic refinery has been installed in the new plant to produce gold of 99.99 per cent purity for specialiged industrial uses.

cathodes. The initial installation comprises a bank of eighteen cells in normal operation with six others for special purposes. Provision has been made for electrolyte circulation, thermostatic control, mechanical agitation and adequate cathode washing facilities. The importance of this new facet of the refinery's operations can be assessed from the fact that it is estimated that the demand for gold for non-monetary purposes is already equal to world production and is still rising.

\title{
Oxygen Coatings on Gold
}

In gold refineries it is widely recognised that ingots newly stripped from moulds may weld together so that they become as one if they are piled one on another while still hot. A favourite explanation for this is that the gold is so soft that the mating surfaces flow so as to touch at every point, valley and high spot in one ingot corresponding with high spot and valley in the other.

This, however, cannot be the whole story. Gold is not so hard at room temperature that equally good contact cannot be secured over a large proportion of the contact area under quite light loads; yet in these conditions, when the gold has cooled, no significant welding is found.

The reason for this is almost certainly that normally in air all gold surfaces are covered with a layer of oxygen which acts as a barrier to perfect welding. The attraction of a gold surface for oxygen at normal temperatures is certainly not large; but it is fascinating to reflect that although air contains only a fifth part by volume of oxygen, a gold surface nevertheless takes the oxygen to itself and rejects the nitrogen absolutely.

The circumstances that govern the nature of the bond-whether the coating is one of a single layer of adsorbed atoms or molecules or whether there is oxide formation-are still not clearly defined. One fact that has been shown conclusively, however, is that invisible surface layers of $\mathrm{Au}_{2} \mathrm{O}$ or $\mathrm{AuO}$ can easily be formed by anodic oxidation at a low voltage in dilute sulphuric acid solution. Several stages have been recognised. The first is the formation of a partial layer of oxygen atoms adsorbed on the surface. On further electrolysis this converts to a layer of $A_{2} \mathrm{O}$ and this in turn converts to AuO.

In normal surroundings of moist air, the most that will occur is the attraction of molecules to the surface, with perhaps some ionisation. The film undoubtedly forms very quickly, but it is easily decomposed and vanishes completely when the gold is heated above about $200^{\circ} \mathrm{C}$. And so a newly cast ingot may be expected to have a noble chemically clean surface until it is cool enough to handle. J. C. C. 